\title{
ESTUDO DA VARIABILIDADE ESPAÇO-TEMPORAL E TENDÊNCIAS DE PRECIPITAÇÃO NA BACIA HIDROGRÁFICA DO RIO PARAÍBA DO SUL
}

\author{
GOMES, Fernanda Bento Rosa - fernanda.bento@engenharia.ufjf.br \\ Universidade Federal de Juiz de Fora / UFJF
}

VARGAS, Isabela Salgado - isabela.vargas@engenharia.ufjf.br Universidade Federal de Juiz de Fora / UFJF

PROCÓPIO, Aline Sarmento - aline.procopio@ufjf.edu.br Universidade Federal de Juiz de Fora / UFJF

CASTRO, Samuel Rodrigues - samuel.castro@ufjf.edu.br Universidade Federal de Juiz de Fora / UFJF

RIBEIRO, Celso Bandeira de Melo - celso.bandeira@ufjf.edu.br Universidade Federal de Juiz de Fora / UFJF

Submetido em: 06/06/2020 Aceito para publicação em: 05/04/2021 Publicado em: $17 / 04 / 2021$ DOI: http://dx.doi.org/10.5380/abclima.v28i0.74380

\begin{abstract}
RESUMO: Este estudo teve como objetivo avaliar a distribuição espacial da precipitação pluviométrica da bacia hidrográfica do rio Paraíba do Sul entre os anos de 1988 a 2018. Para tal, foram adquiridos dados de precipitação acumulada mensal, precipitação máxima mensal e número de dias de chuva no mês, de 86 estações pluviométricas extraídos da plataforma Hidroweb disponibilizada pela Agência Nacional de Águas (ANA). Após análise e tratamento de inconsistências nos dados das séries extraídas, foram realizados cálculos para obtenção das chuvas médias da bacia a partir do método de Thiessen, e realizadas análises estatísticas a fim de avaliar possíveis diferenças significativas entre os meses do ano em relação às precipitações médias acumuladas mensalmente, bem como entre os números de dias de chuva mensais. Foram também construídos mapas de precipitação média mensal acumulada nos períodos seco e chuvoso utilizando-se o método de krigagem ordinária. Confirmou-se, com esse estudo, que a bacia apresenta uma grande variação pluviométrica intra-anual, e que a precipitação acumulada mensal tem significativa correlação $(a=0,05)$ com o número de dias com chuvas, como esperado. Observou-se que há grande variação espacial da pluviometria. Com a aplicação do Índice de Anomalia de Chuva foi possível observar que houve períodos atípicos positivos nos anos de 1996, 2008 e 2009, e negativos no ano de 2014. O teste de Mann-Kendall possibilitou avaliar que algumas estações apresentaram tendências significativas de acréscimo e outras de decréscimo de chuvas, sendo mais evidenciados pelos valores relativos ao número de dias de chuva, chegando à $20,9 \%$ de tendências de acréscimo no semestre chuvoso, a $95 \%$ de confiança, e $22,9 \%$ de tendências significativas de decréscimo no semestre seco. Por fim, com base nos parâmetros Sen's slope, foi evidenciado incremento na probabilidade de ocorrência de eventos extremos diários de chuva em até $10 \%$ da área total da bacia. Os resultados revelaram, portanto, o indício de alterações nos padrões pluviométricos da bacia do Rio Paraíba do Sul.
\end{abstract}

PALAVRAS-CHAVE: Índice de Anomalia de Chuva; mudanças climáticas; seca; tendência de precipitação; pluviometria.

SPATIO-TEMPORAL VARIABILITY AND TRENDS OF RAINFALL IN THE PARAÍBA DO SUL RIVER BASIN 
ABSTRACT: Aiming to observe variability over time in the Paraíba do Sul River basin, this study assessed the spatial distribution of rainfall in this basin between the years 1988 to 2018. For this purpose, monthly data on accumulated rainfall, maximum rainfall, and the number of rainy days regarding 86 pluviometric stations were obtained. After filling missing data from the extracted time series, different analyses were performed. The average basin rainfall was computed using the Thiessen method. Significant differences between monthly average accumulated rainfall as well as between numbers of monthly rainy days were evaluated. Maps of average monthly precipitation accumulated in dry and wet seasons were constructed using the ordinary kriging method. The basin presents a vast intra-annual rainfall variation, and the accumulated monthly precipitation has a statistically significant correlation with the number of rainy days $(a=0.05)$. There is also a large spatial variation in rainfall. With the application of the Rain Anomaly Index, were observed atypical positive periods in years 1996, 2008, and 2009, and a negative one in 2014. The Mann-Kendall test showed trends in rainfall, mainly in number of rainy days, with $20.9 \%$ of increasing trends in the rainy semester, at $95 \%$ confidence level, and $22,9 \%$ of significant decreasing trends in the dry semester. Based on Sen's slope parameters, was evidenced an increase in the probability of extreme rainfall in up to $10 \%$ of the total area of the basin. Therefore, results indicated possible changes in pluviometric patterns in the Paraíba do Sul River basin.

KEYWORDS: climatic changes; drought; precipitation trend; pluviometry; Rain Anomaly Index.

ESTUDIO DE LA VARIABILIDAD ESPACIO-TEMPORAL Y TENDENCIAS DE PRECIPITACIÓN EN LA CUENCA HIDROGRÁFICA DEL RÍO PARAÍBA DO SUL

RESUMEN: Este estúdio tuvo como objetivo evaluar la distribución espacial de la precipitación en la cuenca hidrográfica del río Paraíba do Sul entre los años 1988 y 2018. Con este propósito, se obtuvieron datos mensuales sobre la precipitación mensual acumulada, la precipitación mensual máxima y el número de días lluviosos en el mes de 86 estaciones pluviométricas extraídos de la plataforma Hidroweb proporcionada por la Agência Nacional de Águas (ANA). Tras llenar los datos faltantes de las series extraídas, se realizaron cálculos para obtener la precipitación media de la cuenca utilizando el método de Thiessen, además de análisis estadísticos para averiguar la existencia de diferencias significativas entre la precipitación acumulada media mensual así como entre los números de días lluviosos mensuales. Los mapas de precipitación media mensual acumulada en los semestres secos y lluviosos también fueron construídos utilizando el método de kriging ordinario. Se observó con este estudio que la cuenca presenta una gran variación de precipitación intra-anual y que la precipitación mensual acumulada tiene una correlación significativa $(a=0,05)$ con el número de días lluviosos, como esperado. Hay también una gran variación espacial en la precipitación. Con la aplicación del Índice de Anomalía de Lluvia fue posible observar que hubo períodos atípicos positivos en 1996, 2008 y 2009, además de períodos negativos en 2014. El teste de Mann-Kendall permitió analizar tendencias en el aumento y disminución de la precipitación en algunas estaciones, enfocando el número de días lluviosos, llegando a $20,9 \%$ de tendencias de aumento en el semestre lluvioso, con el $95 \%$ de confianza, y $22,9 \%$ de tendencias significativas de disminución en el semestre seco. Basado en los parámetros Sen's slope, se evidenció un aumento en la probabilidad de ocurrencia de eventos de lluvia diaria extrema en hasta un $10 \%$ del área total de la cuenca. Por lo tanto, los resultados indicaron posibles cambios en los patrones de lluvia en la cuenca del río Paraíba do Sul.

PALABRAS ClAVE: cambios climáticos; Índice de Anomalía de Lluvia; pluviometria; sequía; tendencia de precipitación.

\section{INTRODUÇÃO}

Os estudos sobre mudanças climáticas e eventos extremos vêm se destacando e atraindo atenção em todo o mundo (ANDRADE et al., 2020; 
NUNES et al., 2019; PIAZZA et al., 2016; CONFALONIERI et al., 2014; ZHANG e CONG, 2014; BURN et al., 2011; VILLARINI et al., 2011) e, apesar das discussões existentes sobre o tema, percebe-se que os Relatórios do Painel Intergovernamental de Mudanças Climáticas (IPCC) e a grande maioria da literatura correlata atestam mudanças no comportamento da atmosfera, esta, com tendência de aquecimento global (SILVA et al., 2017). Essas mudanças podem influenciar diversos setores da sociedade, economicamente, socialmente e ambientalmente (HURD e ROUHI-RAD, 2013; CONFALONIERI et al., 2014; LUQUE et al., 2013).

Entre os muitos efeitos das mudanças climáticas, estão as alterações no regime hidrológico (ALMEIDA et al., 2020; FISCH et al., 2017; MARENGO e VALVERDE, 2007; SANCHES et al., 2013), tanto em escala global quanto local (SANTOS et al., 2020; FIGUEIRÓ e NETO, 2011; SANCHES et al., 2013), com um aumento significativo de eventos hidrológicos extremos de secas e chuvas alterando-se, assim, a disponibilidade hídrica de determinada região e, consequentemente, a qualidade de vida da população (COSTA et al., 2015; SILVA et al., 2017; HURD e ROUHI-RAD, 2013).

A Política Nacional de Recursos Hídricos, estruturada consoante a Lei Federal no 9.433/97, estabelece em seus fundamentos o princípio de que a água é um recurso natural limitado, dotado de valor econômico, e a unidade territorial para a gestão dos recursos hídricos é a bacia hidrográfica (BRASIL, 1997). Paralela e conjunta a essa definição, de forma a organizar e compreender o sistema de recursos hídricos, os Planos de Bacia são instrumentos da Lei Federal supracitada para atender as demandas de cada unidade territorial, onde identificam-se ações de interesse diretas ou indiretas para uma gestão integrada dos recursos em longos horizontes (BRASIL, 1997; CEIVAP, 2020a).

Nesse contexto, estudos da distribuição espacial da precipitação sobre a área das bacias hidrográficas se tornam essenciais na avaliação da disponibilidade hídrica frente a seus usos e demandas (DINIZ, 2013; SALVIANO et al., 2016). Paralelamente a isso, a análise de séries históricas é fundamental no estudo das precipitações médias mensais na bacia pois, além de ser uma das maneiras de se investigar a ocorrência de mudança climática local e suas consequências sobre a sociedade, permite compreender, estatisticamente, a tendência de chuvas, gerando informações para previsões futuras a partir de dados passados. Para tal, as ferramentas geoestatísticas são as mais utilizadas (ALMEIDA et al., 2020; REGOTO et al., 2018; SILVA et al., 2017; SANCHES et al., 2013; DUARTE et al., 2007).

A bacia do Rio Paraíba do Sul destaca-se no cenário econômico, por sua localização estratégica, entre os estados de Minas Gerais, Rio de Janeiro, São Paulo, eixo de grande concentração populacional e industrial (CEIVAP, 2020b; DEMANBORO, 2015; AGEVAP, 2011; AGEVAP, 2006). Além disso, a bacia é responsável por grande parte do abastecimento de água da região suprindo, inclusive, outros grandes sistemas de abastecimento público, como os sistemas Cantareira e Guandu (DEMANBORO, 2015; CAVALCANTI e MARQUES, 2016), com uma demanda hídrica total para o abastecimento estimada em mais de 20 $\mathrm{m}^{3} / \mathrm{s}$ (AGEVAP, 2011) e que, segundo dados da Agência Nacional de Águas (ANA), deverá crescer aproximadamente $24 \%$ nos próximos 10 anos (ANA, 2019). 
Diante de eventos hidrológicos de extrema seca, eleva-se a complexidade da gestão dos usos múltiplos aos quais a bacia se destina. Fato que se evidenciou na bacia hidrográfica do Rio Paraíba do Sul durante a crise hídrica de 2014, gerando conflitos pelo uso da água entre setores diversos, destacando-se o abastecimento público e a geração de energia (CAVALCANTI e MARQUES, 2016; GALVÃO e BERMANN, 2015).

Nesse cenário, há o crescente interesse no estudo do comportamento pluviométrico de bacias hidrográficas, tendo em vista a identificação de vulnerabilidades na conjuntura hídrica das bacias e a avaliação de possíveis mudanças climáticas locais por meio da análise de eventos extremos (NUNES et al., 2019; CARVALHO et al., 2017; FISCH et al., 2017; SILVA et al., 2017; PIAZZA et al., 2016; SOUZA et al., 2015; MORAES e NERY, 2014; FIGUEIRÓ e NETTO, 2011; MARENGO e ALVES, 2005). Dessa forma, viabiliza-se a projeção de cenários de possíveis impactos sobre os recursos hídricos que auxiliam a tomada de decisão, estimulam o desenvolvimento de pesquisas e políticas de mitigação das consequências das mudanças climáticas sobre as bacias.

Utilizando-se diferentes séries temporais, estudos de Marengo e Alves (2005) e Andrade e Ribeiro (2018) avaliaram tendências das precipitações médias mensais na bacia do Paraíba do Sul. Com base nas precipitações médias mensais dos anos de 1920 a 2000, Marengo e Alves (2005) não evidenciaram tendências de acréscimo ou decréscimo estatisticamente significativas na bacia. Por outro lado, em análises feitas por Andrade e Ribeiro (2018) com séries entre 1900 e 2017, 15\% das estações pluviométricas apresentaram tendências temporais, sendo metade de acréscimo e outra de decréscimo, com grande parte dessas estações na região da bacia contida no estado de São Paulo. Já Carvalho et al. (2017) e Moraes e Nery (2014) constataram anomalias de extrema seca e extrema chuva também na região paulista da bacia entre os anos de 1976 e 2010.

Diante do exposto, este estudo teve como objetivo avaliar a distribuição espacial e temporal da precipitação sobre toda a extensão da bacia hidrográfica do Rio Paraíba do Sul entre os anos de 1988 a 2018, bem como analisar a ocorrência de anomalias e averiguar eventuais tendências na ocorrência de eventos extremos de seca e chuva na região.

\section{MATERIAL E MÉTODOS}

\subsection{CARACTERIZAÇÃO DA BACIA}

A bacia hidrográfica do Rio Paraíba do Sul (Figura 1) possui área de cerca de $62.074 \mathrm{~km}^{2}$, abrangendo estados de grande relevância política, social e econômica: São Paulo, Rio de Janeiro e Minas Gerais (AGEVAP, 2006, CEIVAP, 2020b).

Componente principal e determinante da bacia do Rio Paraíba do Sul, o rio de mesmo nome possui comprimento de aproximadamente $1.150 \mathrm{~km}$ contados desde sua nascente na Serra da Bocaína até sua foz no município de São João da Barra. O Rio Paraíba do Sul configura-se como de extrema importância no cenário nacional e é formado pela união dos rios Paraibuna e Paraitinga (CAVALCANTI e MARQUES, 2016). 

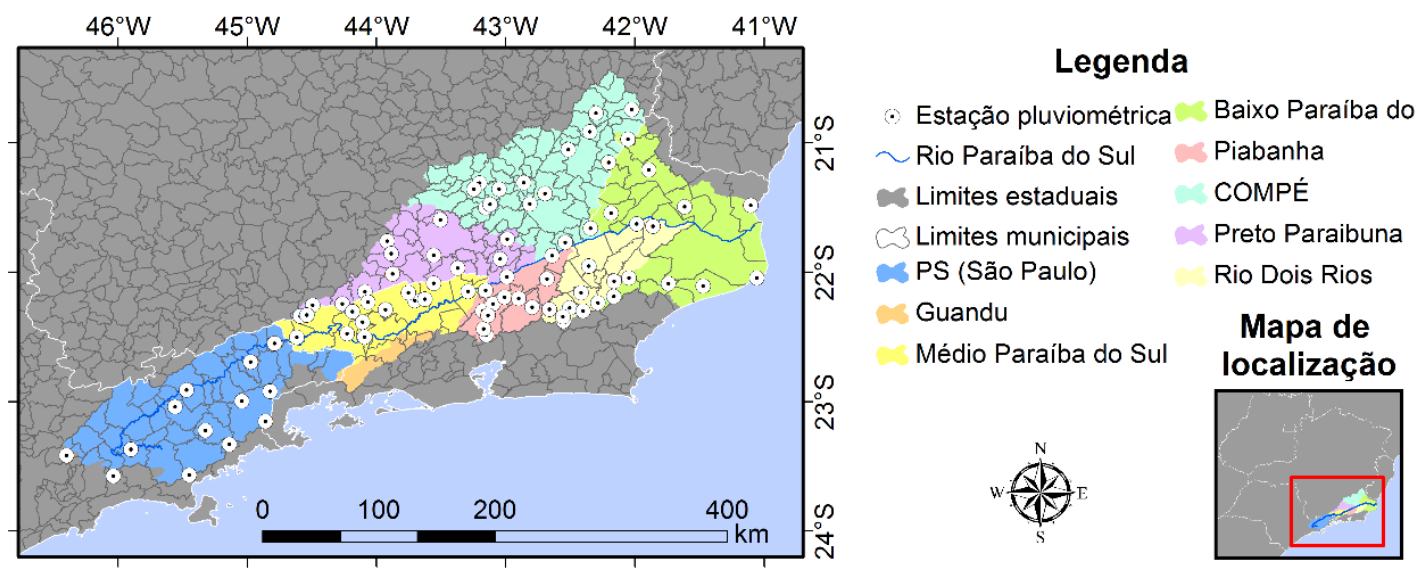

Fonte de dados: Rede Hidrometeorológica Nacional (2019); SIGA CEIVAP (2019); IBGE (2019) Datum: WGS-84

Figura 1 - Delimitação da Bacia Hidrográfica do Rio Paraíba do Sul bem como suas UPHs e localização das estações pluviométricas selecionadas neste estudo.

Seus principais afluentes da margem esquerda são os rios Jaguari, Pirapetinga, Pomba, Paraibuna, Muriaé, e da margem direita os rios Piraí, Piabanha, Bananal, Una e Dois Rios (AGEVAP, 2006). Também, graças aos afluentes, a bacia como um todo possui diversos aproveitamentos de usos múltiplos da água, visando a regularização de vazões, o controle de cheias, a geração de energia hidroelétrica, consumo para processos produtivos e agricultura, diluição de esgotos e, em menor escala, pesca, aqüicultura, recreação e navegação; além de abastecer cerca de 14,2 milhões de pessoas (MARENGO e ALVES, 2005; CAVALCANTI e MARQUES, 2016).

Segundo a AGEVAP (2014), a bacia do Rio Paraíba do Sul pertence à região hidrográfica do Atlântico Sudeste, ao passo em que é subdividida em oito Unidades de Planejamento Hídrico (UPHs), nas quais atuam diferentes comitês de bacia hidrográfica $(\mathrm{CBH})$, sendo: $\mathrm{CBH}$ Paraíba do Sul (São Paulo), $\mathrm{CBH}$ Guandu, CBH Médio Paraíba do Sul, CBH Baixo Paraíba do Sul, CBH Piabanha, CBH COMPÉ (Pomba e Muriaé), CBH Preto Paraibuna e CBH Rio Dois Rios (Figura $1)$.

Em relação ao clima da região, é predominantemente tropical quente e úmido, com variações determinadas pelas diferenças de altitude e entradas de ventos marinhos (CEIVAP, 2020b), com temperaturas médias anuais variando de $18^{\circ}$ a $24^{\circ} \mathrm{C}$ (AGEVAP, 2014; MORAES e NERY, 2014).

\subsection{LEVANTAMENTO DE DADOS DE ESTAÇÕES PLUVIOMÉTRICAS, ANÁLISES E TRATAMENTO DE INCONSISTÊNCIAS NAS DISTRIBUIÇÕES DE DADOS}

Dados mensais referentes às estações pluviométricas foram extraídos por meio da plataforma Hidroweb (2020), disponibilizada pela ANA. Foram selecionadas estações pluviométricas pertencentes à bacia do Rio Paraíba do Sul, cujas séries temporais compreendiam o intervalo de 1988 a 2018 . No total, foram reunidos dados de 86 estações pluviométricas instaladas ao longo da bacia (Figura 1), localizadas conforme disposto no Documento Suplementar 1 (Tabela DS1.1). Dessa forma, foram agregados dados referentes à precipitação 
acumulada mensal, precipitação máxima mensal e número de dias de chuva no mês, e dados de precipitação diária (Figura 2).

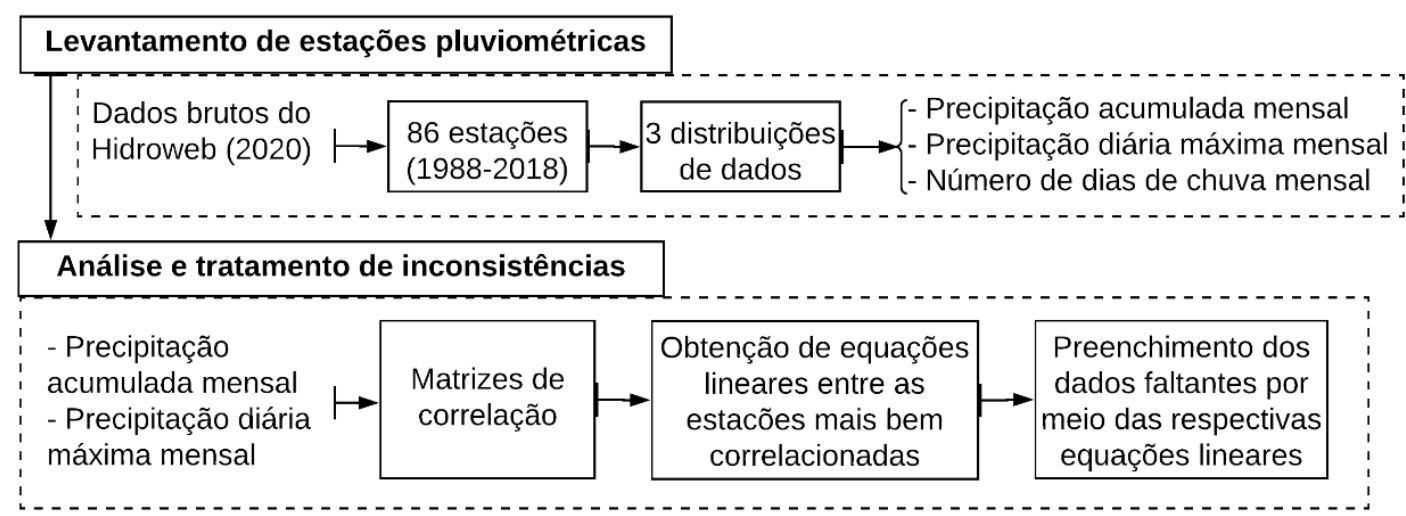

Figura 2 - Sistematização da obtenção e preenchimento de falhas dos dados pluviométricos.

Verificou-se a existência de dados faltantes nas séries temporais, como inconsistência, referentes tanto à precipitação acumulada mensal quanto à precipitação máxima mensal. Para cada tipo de distribuição (precipitação máxima e precipitação acumulada) foi obtida uma matriz de correlação linear entre as estações pluviométricas, com vistas a identificação de pares de estações pluviométricas com coeficientes de correlação mais próximos à unidade. Em seguida, foram construídos gráficos de dispersão dos pares correlacionados, por meio dos quais foram extraídas equações lineares, empregadas na obtenção de valores adotados no preenchimento dos dados faltantes das séries temporais de cada estação pluviométrica, conforme Zeilhofer et al. (2003).

\subsection{DISTRIBUIÇÃO INTRA-ANUAL DE CHUVAS NA BACIA}

\subsubsection{ANÁLISE TEMPORAL DAS CHUVAS MENSAIS}

Com vistas a análise do comportamento das chuvas ao longo dos meses, foram feitos cálculos das alturas pluviométricas médias das precipitações acumuladas mensais e dos acumulados de dias de chuva mensais de cada ano entre 1988 e 2018, utilizando se o método de Thiessen (1911). Por meio desse método, foram determinadas as áreas de influência de cada uma das estações pluviométricas selecionadas neste estudo e, a essas áreas, foram associados valores de precipitação (Tucci, 1997). Dessa forma, o cálculo das precipitações médias foi ponderado pela área de influência de cada estação, considerando a não uniformidade na distribuição espacial das mesmas.

A partir de então, foram construídos gráficos relativos às precipitações acumuladas e números de dias de chuva mensais para a série temporal de 1988 a 2018. Em seguida, buscou-se avaliar a existência de possíveis diferenças significativas, a $95 \%$ de confiança, entre todos os meses do ano em relação às precipitações médias acumuladas mensalmente, bem como entre os números de dias de chuva mensais, visando analisar a sazonalidade das chuvas na bacia. Para isso, verificou-se a aderência das distribuições à distribuição normal pelo teste qui-quadrado (PEARSON, 1900). Com a constatação da não-normalidade 
de tais distribuições, aplicou-se o teste de Kruskal-Wallis (KRUSKAL e WALLIS, 1952) e comparações múltiplas a $95 \%$ de confiança.

\subsubsection{ANÁLISE ESPACIAL DAS CHUVAS SAZONAIS}

Segundo a ANA (2011), a bacia hidrográfica do Rio Paraíba do Sul apresenta estações seca e chuvosa bem definidas, com períodos de maior pluviosidade de novembro a março e menor pluviosidade entre junho e agosto, com períodos de transição entre estações nos demais meses. Nesse sentido, para efeitos desse estudo foram definidos dois períodos para a análise espacial das chuvas, estabelecidos com base no exposto pela ANA (2011). Os meses de transição foram distribuídos com base em sua pluviosidade média. Dessa forma, foram agrupados os seis meses com maior e menor quantitativos de chuva, sendo: abril a setembro (semestre mais seco) e outubro a março (semestre mais chuvoso), respectivamente.

Em seguida, foram construídos mapas de precipitação média mensal acumulada nos dois semestres, por meio da interpolação das médias dos dados coletados de cada estação de monitoramento, utilizando-se o método de krigagem ordinária (CRESSIE, 1990).

Como forma complementar às discussões, foi feita a representação espacial da altitude e das tipologias climáticas da bacia. A espacialização da altitude foi feita a partir de um modelo digital de elevação (MDE) composto por 11 imagens com resolução espacial de $90 \mathrm{~m}$ da Shuttle Radar Topography Mission (SRTM), sendo: SF-23-X-B; SF-23-X-C; SF-23-X-D; SF-23-Y-B; SF-23Y-D; SF-23-Z-A; SF-23-Z-B; SF-23-Z-C; SF-24-V-A; SF-24-V-C; e SF-24-Y-A (USGS, 2004). Já as classificações climáticas de Köppen-Geiger (KÖPPEN, 1936) foram obtidas a partir do estudo de Alvares et al. (2014).

\subsection{DISTRIBUIÇÃO INTERANUAL DAS PRECIPITAÇÕES NA BACIA E AVALIAÇÃO DE ANOMALIAS ENTRE 1988 E 2018}

\subsubsection{ANÁLISE DA PLUVIOSIDADE ANUAL}

Para a avaliação da variabilidade da chuva ao longo dos anos, as precipitações acumuladas e números de dias de chuvas na bacia em cada ano entre 1988 e 2018 foram calculados pelo método de Thiessen (1911). As séries temporais obtidas foram representadas graficamente, sendo extraídos ainda: o mínimo, máximo, média, desvio padrão e mediana de cada distribuição. Como parâmetro de análise comparativa das chuvas calculou-se a precipitação acumulada anual média da bacia relativa a todo o período de 1988 a $2018 \mathrm{com}$ dados de todas as 86 estações pluviométricas (Hidroweb, 2020), também pelo método de Thiessen (1911).

\subsubsection{DETERMINAÇÃO DOS ÍNDICES DE ANOMALIA DE CHUVA (IAC)}

Para caracterizar a variabilidade da precipitação e corroborar a identificação de anomalias anuais, foi utilizado o Índice de Anomalia de Chuva (IAC), analisando a frequência e intensidade dos anos secos e chuvosos na área 
estudada, a partir dos 31 anos de dados históricos médios anuais de chuva obtidos, conforme descrito no item anterior (2.4.1).

O IAC foi proposto inicialmente por Rooy (1965) e adaptado por Freitas (2005). Neste estudo, utilizou-se a classificação de anos secos e chuvosos, proposta por Freitas (2005) e adaptada por Araújo et al. (2009), dada pelas Equações 1 e 2:

$$
\begin{aligned}
& I A C=3\left[\frac{(N-\bar{N}}{(\bar{M}-\underline{N})}\right] \\
& I A C=-3\left[\frac{(N-\bar{N})}{(\overline{\mathrm{X}}-\bar{N})}\right]
\end{aligned}
$$

sendo: $N$ a precipitação mensal atual $(\mathrm{mm}) ; \overline{\mathrm{N}}$ a precipitação média mensal da série temporal ( $\mathrm{mm}$ ); $\overline{\mathrm{M}}$ a média das dez maiores precipitações mensais da série $(\mathrm{mm})$; e $\overline{\mathrm{X}}$ a média das dez menores precipitações mensais da série $(\mathrm{mm})$. A Equação 1 é utilizada no cálculo de anomalias positivas, ao passo em que a Equação 2 é aplicada para anomalias negativas.

Nessa metodologia, as anomalias são classificadas da seguinte forma: IAC $\leq-4$ : extremamente seco; $-4<$ IAC $\leq-2$ : muito seco; $2<$ IAC < 0: seco; IAC $=0$ : nem seco nem chuvoso; $0<$ IAC $\leq 2$ : chuvoso; $2<$ IAC $\leq 4$ : muito chuvoso; IAC $\geq 4$ : extremamente chuvoso.

O trabalho realizado por Carvalho et al. (2017) para a Unidade de Gerenciamento dos Recursos Hídricos do Paraíba do Sul (UGRHI-02), concluiu que para essa região tal índice é o mais apropriado para ser utilizado no planejamento da gestão hídrica, por ser mais eficaz e preciso para classificar e delimitar períodos de grande seca e chuva intensa. Assim, espera-se que o uso do IAC possa ajudar na interpretação e visualização da variação anual pluviométrica durante a série temporal estudada, como nos estudos de Maniçoba et al. (2017) e Moraes e Nery (2014).

\subsubsection{ESTUDO DE CASO DE EXTREMOS ANUAIS}

Para efeitos de discussão, foram selecionados os dois anos de precipitações mais atípicas na bacia entre 1988 e 2018, sendo um extremo de seca e um extremo de chuva. Para estes dois anos, foi feita a representação gráfica das precipitações mensais diante das precipitações mensais médias da bacia calculadas para o período de 1988 a 2018, bem como a representação espacial dos desvios da precipitação em relação às médias da bacia (1988-2018) nos semestres secos e chuvosos. A determinação dos desvios baseou-se nas médias mensais dos semestres mais secos e mais chuvosos obtidas para cada estação pluviométrica, tal como especificado no Item 2.3.2, utilizando-se a Equação 3:

$$
\text { Desvio }=N-\bar{N}
$$

onde: $N$ é a chuva média mensal da estação pluviométrica do semestre (mais seco ou mais chuvoso) no ano extremo; e $\bar{N}$ a chuva média mensal da estação pluviométrica do semestre (mais seco ou mais chuvoso) considerando a totalidade da série temporal (1988-2018). De posse dos desvios de cada estação, foram construídos mapas interpolados por krigagem ordinária no ArcGIS 10.5 (CRESSIE, 1990). 


\subsection{ANÁLISE DE TENDÊNCIAS TEMPORAIS DA PRECIPITAÇÃO}

O teste de Mann-Kendall (MANN, 1945; KENDALL e STUART, 1967) consiste em um método não paramétrico para a verificação da existência de tendências temporais. Esse teste vem sendo amplamente utilizado em estudos hidrológicos, inclusive na avaliação mudanças climáticas locais (ANDRADE e RIBEIRO, 2018; SALVIANO et al., 2016; SANCHES et al., 2013; SANTOS et al., 2020; PIAZZA et al., 2016; ZHANG e CONG, 2014; BURN et al., 2011; SHAHID, 2011; VILLARINI et al., 2011)

Tendo em vista a avaliação da propensão à eventos extremos de chuva e seca na bacia, avaliou-se a tendência da precipitação diária máxima mensal, bem como do número total de dias de chuva no mês. Os dados referentes a precipitação máxima mensal e número de dias de chuva nos semestres de seca (meses de abril a setembro) e chuva (meses de outubro a março) de cada estação pluviométrica entre os anos de 1988 a 2018 foram dispostos no software $R$ e, por meio do pacote estatístico Kendall (MCLEOD, 2015), foram feitas análises de tendência temporal utilizando-se o método de Mann-Kendall, com intervalo de confiança de $95 \%$. A magnitude das tendências foi obtida por meio do coeficiente de Sen (Sen's slope) (SEN, 1968), conforme Hirsch et al. (1991). O detalhamento de tais análises foi disposto no Documento Suplementar 2 (Tabela DS2.1).

Além disso, foram representadas áreas de possíveis tendências de alterações pluviométricas, utilizando-se áreas de influência de cada estação calculadas anteriormente pelo método de Thiessen (determinadas no item 2.3.1).

\section{RESULTADOS E DISCUSSÃO}

\subsection{ANÁLISES E TRATAMENTO DE INCONSISTÊNCIAS NAS DISTRIBUIÇÕES DE DADOS}

Os dados obtidos na base do Hidroweb (2020), relativos à precipitação acumulada mensal e precipitação diária máxima mensal nas 86 estações pluviométricas que foram objeto desse estudo, apresentaram $1,8 \%$ e $2 \%$ de dados faltantes, respectivamente. Os pares de estações pluviométricas com dados de chuva mensal acumulada mais bem correlacionados apresentaram coeficiente de correlação variando de 0,61 a 0,93. No caso da precipitação diária máxima, os dados demonstraram-se menos correlacionados e os coeficientes dos pares de estações de maior correlação mantiveram-se entre 0,42 e 0,8. Portanto, verifica-se que a metodologia empregada foi mais assertiva quando empregada aos dados acumulados, visto que as precipitações máximas diárias tendem a sofrer maior influência das variações microclimáticas.

\subsection{DISTRIBUIÇÃO INTRA-ANUAL DE CHUVAS NA BACIA}

As precipitações médias da bacia acumuladas e o número de dias de chuvas no mês encontrados nesse estudo mostram que, na bacia do rio do Paraíba do Sul, há uma grande variação pluviométrica intra-anual (Figura DS2.1-Figura DS2.12). Com base nos dados mensais de 1988 a 2018, as alturas 
máximas de chuva acumulada mensal ocorreram no mês de janeiro, variando de $96 \mathrm{~mm}$ (2015) a $401 \mathrm{~mm}$ (2007), com valores mais frequentes entre 225 e 250 $\mathrm{mm}$ (Figura DS2.1). Os maiores quantitativos de dias de chuvas ocorreram com maiores frequências nos meses de dezembro e janeiro, com variação de 12 a 14 dias de chuva mensais (Figura DS2.1; Figura DS2.12). Por outro lado, precipitações acumuladas mensais mínimas foram mais frequentes em agosto, mantendo-se inferior a $25 \mathrm{~mm}$ em 52\% dos meses de agosto entre 1988 e 2018 (Figura DS2.8). Já os meses com menor frequência de dias chuvosos foram julho e agosto, variando de 2 a 4 dias (Figura DS2.7; Figura DS2.8). Em média, dezembro de 2005 foi o mês com maior pluviosidade diária, superando 22 $\mathrm{mm} /$ dia de chuva (Figura DS2.12). A menor pluviosidade diária média foi observada em junho do mesmo ano, sendo inferior a $2.5 \mathrm{~mm} /$ dia de chuva no mês (Figura DS2.6).

De acordo com os resultados do teste de comparações múltiplas, não se evidenciaram diferenças significativas entre as precipitações de meses do semestre chuvoso (novembro a março), bem como entre meses do semestre seco (maio a setembro, sem diferenças significativas), a 95\% de confiança. Pode-se perceber que os dados obtidos no presente trabalho estão em concordância com aqueles fornecidos pela ANA (2011) e reportados na literatura (MARENGO e ALVES, 2005; SANT'ANNA NETO, 2005; SILVA et al., 2019). Os dados evidenciam uma estação chuvosa bem definida nos meses de novembro a março, responsável por $72 \%$ da precipitação total anual, caracterizada pelo domínio da massa de ar Continental Equatorial úmida e instável, resultando em elevada umidade relativa do ar e índice de precipitação alto. Verificou-se, ainda, estação seca bem definida nos meses de junho a agosto, caracterizada por condições tropicais de natureza continental e baixa umidade relativa do ar (ANA, 2011; MARENGO e ALVES, 2005 MARENGO e ALVES, 2005; SANT'ANNA NETO, 2005; SILVA et al., 2019).

Em geral, a pluviometria ocorrida nessa região decorre da colisão de massas polares e tropicais de origem atlântica, bem como das linhas de instabilidade de noroeste oriundas da interação de brisas marítimas e ventos alísios (NIMER, 1972; SANT'ANNA NETO, 2005; SOBRAL et al., 2018). Além disso, o Anticiclone Subtropical do Atlântico Sul (ASAS) e o Jato de Baixos Níveis (JBN) são responsáveis pelo transporte de umidade oceânica e amazônica para região, exercendo papeis imprescindíveis na constituição da pluviometria da região durante o semestre chuvoso, principalmente por meio formação da Zona de Convergência do Atlântico Sul (ZCAS) (SILVA et al., 2019; SOBRAL et al., 2018; MARENGO e ALVES, 2005; SANT'ANNA NETO, 2005; NIMER, 1972).

A Figura 3 contém as distribuições espaciais interpoladas referentes à precipitação média mensal acumulada na bacia do Rio Paraíba do Sul ao longo dos meses do semestre mais seco (abril a setembro) e mais chuvoso (outubro a março), considerando a série temporal de 1988 a 2018. 


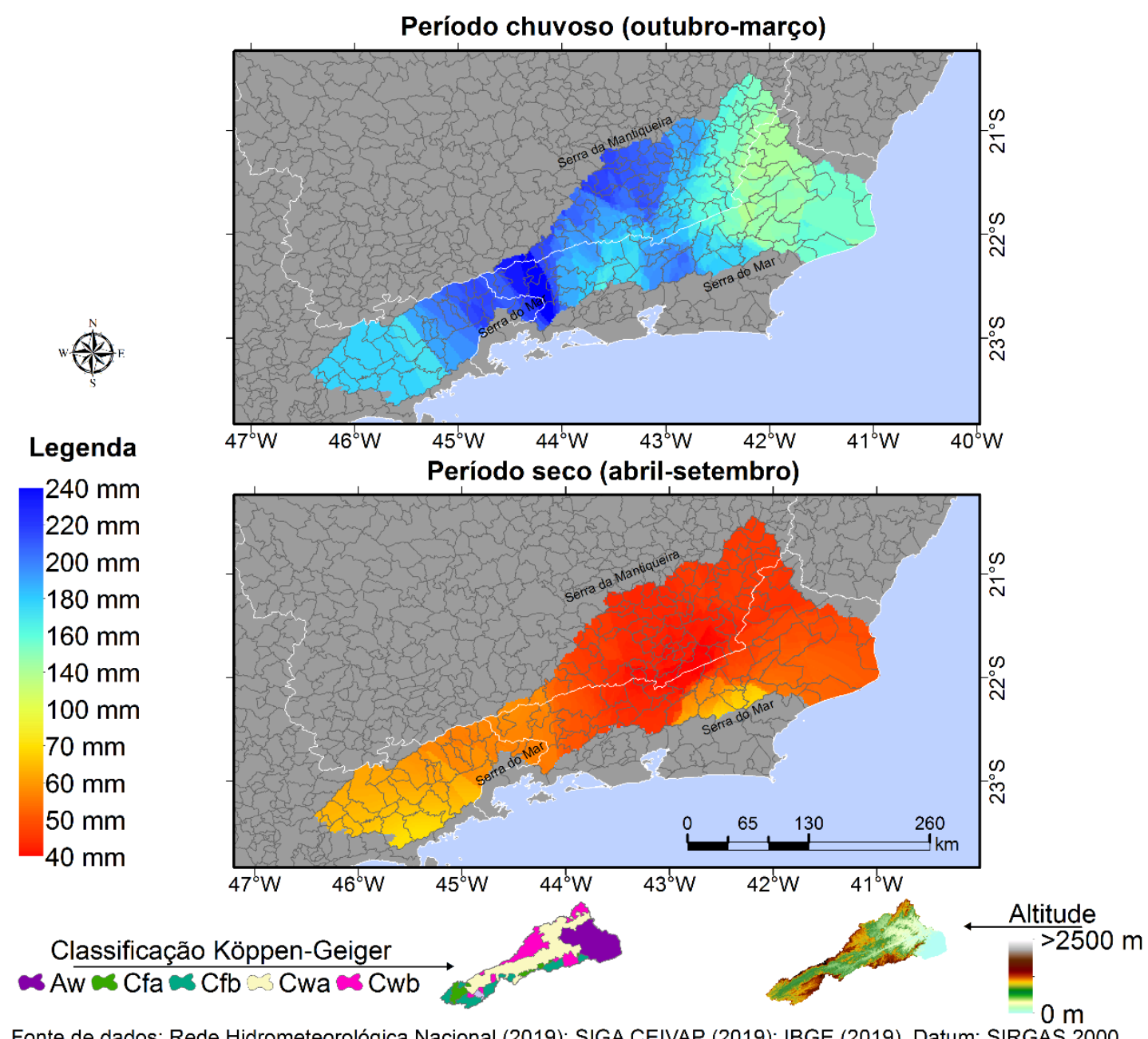

Fonte de dados: Rede Hidrometeorológica Nacional (2019); SIGA CEIVAP (2019); IBGE (2019). Datum: SIRGAS 2000

Figura 3 - Precipitações médias acumuladas mensais na bacia hidrográfica do Rio Paraíba do Sul nos semestres de seca e chuva. Aw: tropical com inverno seco; Cfa: subtropical com verão quente; Cfb: temperado com verão ameno; Cwa: subtropical de inverno seco; Cwb: clima subtropical de altitude, com inverno seco e verão ameno.

A pluviosidade da região tende a ocorrer de forma mais intensa nos pontos de maior altitude, concentrando-se, principalmente, ao longo dos trechos das serras da Mantiqueira e do Mar pertencentes à bacia (Figura 3), favorecendo-se da convecção forçada provocada pelas barreiras orográficas (NIMER, 1972; SANT'ANNA NETO, 2005). Nas regiões próximas a Serra da Mantiqueira, por exemplo, a precipitação média acumulada chega a superar 240 $\mathrm{mm} / \mathrm{mês}$ no semestre chuvoso (Figura 3), conforme também destacado por Sant'anna Neto (2005) e Sobral et al. (2018). Já em outros pontos próximos à Serra do Mar, como na Serra da Bocaína e dos Órgãos, a pluviosidade média nos meses de outubro a março excede $200 \mathrm{~mm} / \mathrm{mês}$ (Figura 3), aspecto também descrito em estudos anteriores (GOIS et al., 2019; SOBRAL et al., 2018; CARVALHO et al., 2017; FIGUEIRÓ e NETO, 2011; SANT'ANNA NETO, 2005).

Além desse mecanismo, a espacialização das chuvas também pode ser influenciada pela variabilidade de tipos climáticos da região (SANT'ANNA NETO, 2005). Conforme apreendido na Figura 3, de acordo com a classificação 
climática de Köppen-Geiger (KÖPPEN, 1936) aplicada no Brasil por Alvares et al. (2014), na bacia do Paraíba do Sul encontram-se distribuídos cinco tipos climáticos.

Essa distribuição varia de tipologias mais quentes e sazonalmente secas (Aw), quase que na totalidade da extensão do Baixo Paraíba do Sul e parte de COMPÉ e Rio Dois Rios, as tipologias úmidas e de temperaturas mais amenas (Cfb), encontradas próximas a regiões serranas dos CBHs Piabanha, Rio Dois Rios e Baixo Paraíba do Sul, e em alguns extremos do CBH PS, nas quais verificam-se maiores pluviosidades nos meses de inverno comparativamente às demais regiões da bacia.

Fatores diversos como o uso do solo também contribuem com a variabilidade da distribuição de chuvas, por intermédio das alterações na temperatura da superfície. Dessa forma, a urbanização vem a favorecer mecanismos convectivos e frontais de formação de chuvas, nas chamadas ilhas de calor (FIGUEIRÓ e NETTO, 2011; JARDIM e MOURA, 2018).

\subsection{DISTRIBUIÇÃO INTERANUAL DAS PRECIPITAÇÕES NA BACIA E AVALIAÇÃO DE ANOMALIAS ENTRE 1988 E 2018}

As precipitações médias acumuladas anuais calculadas para a bacia do Rio do Paraíba do Sul mostram que a região apresentou uma relativa variação pluviométrica entre 1988 e 2018, com desvio padrão de 180,6 mm, indo de 876 a $1741,2 \mathrm{~mm}$, ou seja, amplitude de $865,2 \mathrm{~mm}$ (Tabela 1).

Tabela 1 - Valores das precipitações médias acumuladas anuais da bacia hidrográfica do Rio Paraíba do Sul entre 1988 e 2018.

\begin{tabular}{llllll}
\hline & Mínimo & Máximo & Mediana & Média & Desvio padrão \\
\hline $\begin{array}{l}\text { Precipitação } \\
\text { acumulada anual } \\
\text { (mm) }\end{array}$ & 876,0 & 1741,2 & 1350,6 & 1360,0 & 180,6 \\
$\begin{array}{l}\text { Acumulado anual } \\
\text { de dias de chuva }\end{array}$ & 78 & 131 & 107 & 108 & 11 \\
\hline
\end{tabular}

A partir da Figura 4, observa-se a presença de quatro anos abaixo (1990, 1993, 2014 e 2017) e quatro acima (1996, 2004, 2008 e 2009) do desvio padrão.

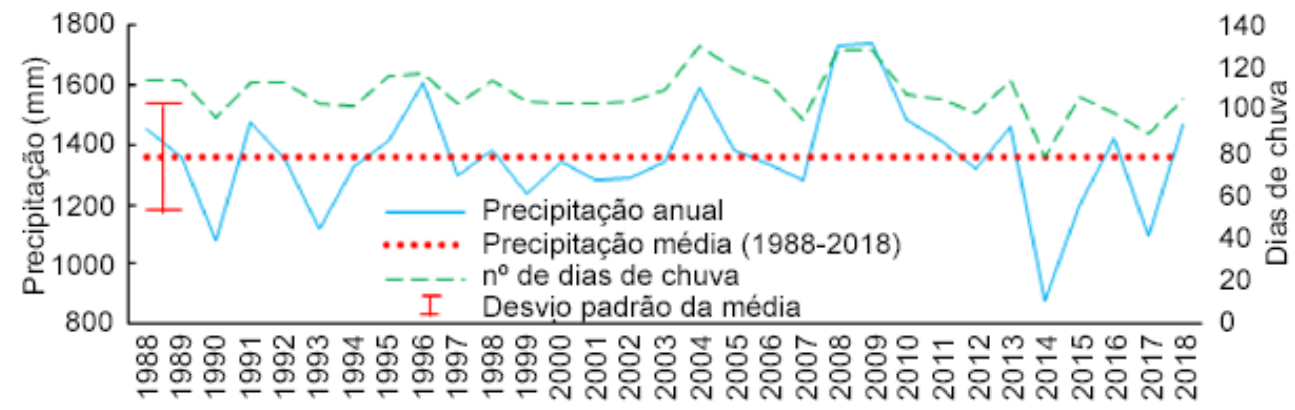

Figura 4 - Precipitações médias acumuladas anuais da bacia hidrográfica do Rio Paraíba do Sul entre 1988 e 2018. 
A partir da aplicação do IAC (Figura 5), foi possível observar que houve um período de quatro anos consecutivos com anomalia positiva de precipitação. Tal fato pode ser observado entre os anos de 2008 e 2011, chegando a valores de IAC de até 6,23 no ano de 2009, configurando classificação "extremamente chuvoso". Por outro lado, verificou-se um período de cinco anos consecutivos de anomalia negativa, entre os anos de 1999 e 2003, porém menos intensa (até 2), semelhante à observação de Marengo e Alves (2005) para a mesma época na avaliação da tendência negativa de chuva. Além disso, percebe-se um maior pico no ano de 2014, chegando ao valor de -7,86, configurando uma classe de intensidade "extremamente seco", sendo quase o dobro do valor limite desse índice (-4), além de ser seguido de um ano com índice "muito seco". Esse pico negativo de 2014 também é percebido na Figura 4, tendo pluviometria acumulada anual de apenas $73 \mathrm{~mm} / \mathrm{mês}$, estando $155 \%$ inferior à precipitação acumulada média para a bacia.

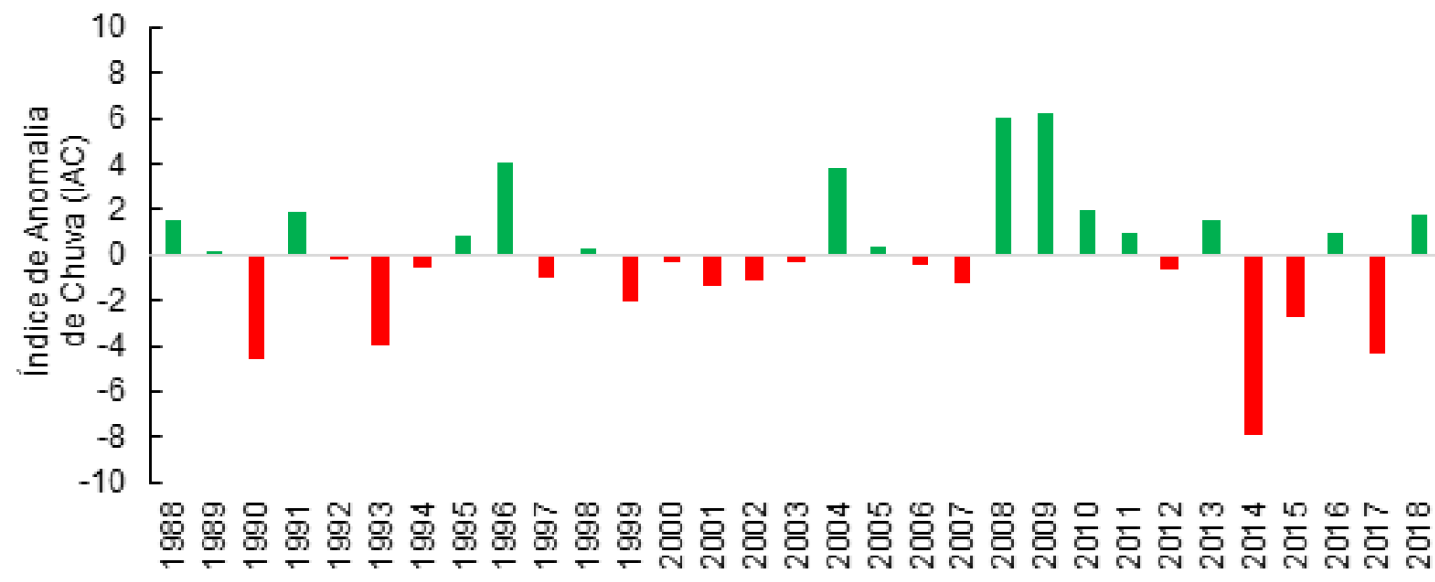

Figura 5 - Índice de Anomalia de Chuva calculado para a série temporal de 1988 a 2018, da bacia hidrográfica do Rio Paraíba do Sul.

Os valores do IAC variaram em uma amplitude de aproximadamente 14, e a ocorrência de anomalias negativas e positivas foram praticamente iguais, (15 valores positivos contra 16 negativos), sendo a única diferença entre a quantidade de valores positivos e negativos o valor de "muito seco" a mais que um valor de "muito chuvoso" (Tabela 2).

Tabela 2 - Número de ocorrências de anomalias classificadas segundo Araújo et al. (2009).

\begin{tabular}{cccccc}
\hline $\begin{array}{c}\text { Extremamente } \\
\text { seco }\end{array}$ & $\begin{array}{c}\text { Muito } \\
\text { seco }\end{array}$ & Seco & Chuvoso & $\begin{array}{c}\text { Muito } \\
\text { chuvoso }\end{array}$ & $\begin{array}{c}\text { Extremamente } \\
\text { chuvoso }\end{array}$ \\
\hline 3 & 2 & 11 & 11 & 2 & 2 \\
\hline
\end{tabular}

Nesse sentido, conforme previamente indicado na Figura 4 e com base nos resultados do IAC (Figura 5), destacam-se, portanto, os anos de 2009 e 2014, com as precipitações anuais mais atípicas na bacia entre 1988 e 2018. Diante do exposto, os tópicos posteriores contemplam uma breve análise do comportamento pluviométrico das anomalias de extrema seca (2014) e extrema chuva (2009) dos referidos anos. 


\subsubsection{ESTUDO DA ANOMALIA DE 2014}

A Figura 6 apresenta a variação mensal e os desvios das precipitações de 2014 em relação à precipitação acumulada média para a bacia entre 1988 e 2018. Pode-se observar valores inferiores à precipitação média, especialmente entre os períodos mais secos (dezembro a março) (Figura 6a). Em janeiro desse ano, a chuva foi, em média para a bacia, menor que a metade do valor da precipitação acumulada média para a bacia (101,4mm de chuva). Continuando, oito dos doze meses do ano de 2014 (fevereiro, março, maio, setembro, outubro, novembro e dezembro) foram de baixa pluviometria (mínimo de $25,3 \mathrm{~mm})$.

Por meio da Figura 6b, verifica-se que os desvios em relação à média de 1988-2018 mantiveram-se entre -75 e $-100 \mathrm{~mm} / \mathrm{mês}$ na maior parte da bacia. Foram observadas anomalias pontuais e distribuídas superando $-185 \mathrm{~mm} / \mathrm{mês}$, com destaque para estações dos municípios de Resende-RJ (2244030) e Juiz de Fora-MG (2143020), com desvios médios mensais superiores a -200 mm/mês.

Entre abril e setembro, as anomalias negativas ocorreram de forma mais intensa no estado de São Paulo (CBH PS), com valores próximos a $-50 \mathrm{~mm} / \mathrm{mês}$ (Figura 6c), chegando a -85 mm/mês em Natividade da Serra-SP (2345176).
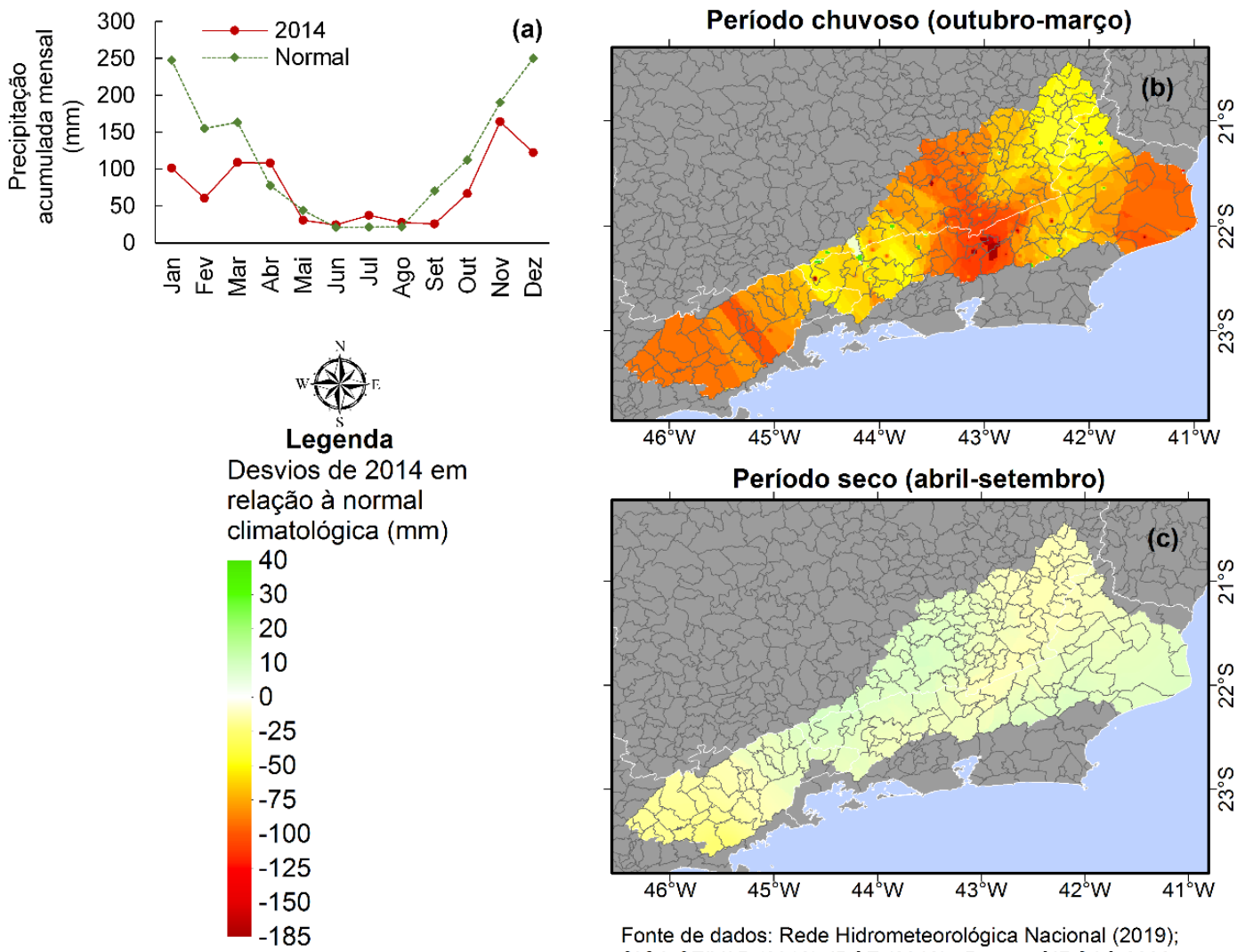

Fonte de dados: Rede Hidrometeorológica Nacional (2019); SIGA CEIVAP (2019); IBGE (2019) Datum: SIRGAS 2000

Figura 6 - a) Variação temporal da precipitação acumulada mensal de 2014 e a precipitação acumulada média (1988-2018) da bacia; b) Distribuição espacial dos desvios de precipitação em 2014 em relação à precipitação acumulada média (19882018) da bacia para o semestre chuvoso; c) Distribuição espacial dos desvios de precipitação em 2014 em relação à precipitação acumulada média (1988-2018) da bacia para o semestre seco. 
De acordo com trabalho realizado por Marengo et al. (2015) sobre a bacia do Cantareira (SP), a pluviometria de janeiro de 2014 foi de apenas 87,9 $\mathrm{mm}$ (67\% abaixo da média histórica). Esse estudo, aliado ao de Nobre et al. (2016), reportou que baixas pluviometrias nos meses de dezembro de 2013 a fevereiro de 2014 estavam relacionadas à ocorrência de um sistema de alta pressão (anticiclone) anômalo sobre o Oceano Atlântico subtropical, que prejudicou o transporte de umidade da Amazônia, através dos rios voadores, e a passagem/desenvolvimento dos principais sistemas causadores de chuva, como a ZCAS e as frentes frias. Segundo esses autores, o mês de janeiro de 2014 foi o mês mais seco da história dos últimos 52 anos na região.

Porém, segundo próprio Marengo et al. (2015) e Cavalcanti e Marques (2016), além do fator ausência de chuvas, como evidenciado nesse trabalho, e por Galvão e Bermann (2015), a crise hídrica em 2014 foi causada, dentre outros motivos, pelo rápido crescimento populacional e alta taxa de urbanização aliados à falta de planejamento, desmatamento e poluição dos rios. De acordo com Matsushita e Granado (2017) e CEIVAP (2020b), mais de 1 bilhão de litros de esgoto são lançados por dia na bacia do Paraíba do Sul; mais de 8 mil indústrias retiram água do rio e lançam cerca de 30 milhões de toneladas de efluentes diariamente.

\subsubsection{ESTUDO DA ANOMALIA DE 2009}

As épocas de estiagem são prejudiciais para o abastecimento público, para as atividades de agroindústria e agropecuária, pesca, para geração de energia, traz impactos socioeconômicos nas áreas que exploram o turismo e lazer, podem aumentar focos de queimadas, além de ser prejudicial para os ambientes naturais que dependem daquele recurso (FREITAS e KAETSU, 2015; MARENGO et al., 2015; DINIZ et al., 2013). Porém, as chuvas intensas, também podem ser prejudiciais, uma vez que podem causar inundações e erosão no solo (ARAÚJO et al., 2008). A Figura 7 apresenta a variação mensal e os desvios das precipitações de 2009 em relação à precipitação acumulada média para a bacia entre 1988 e 2018. 

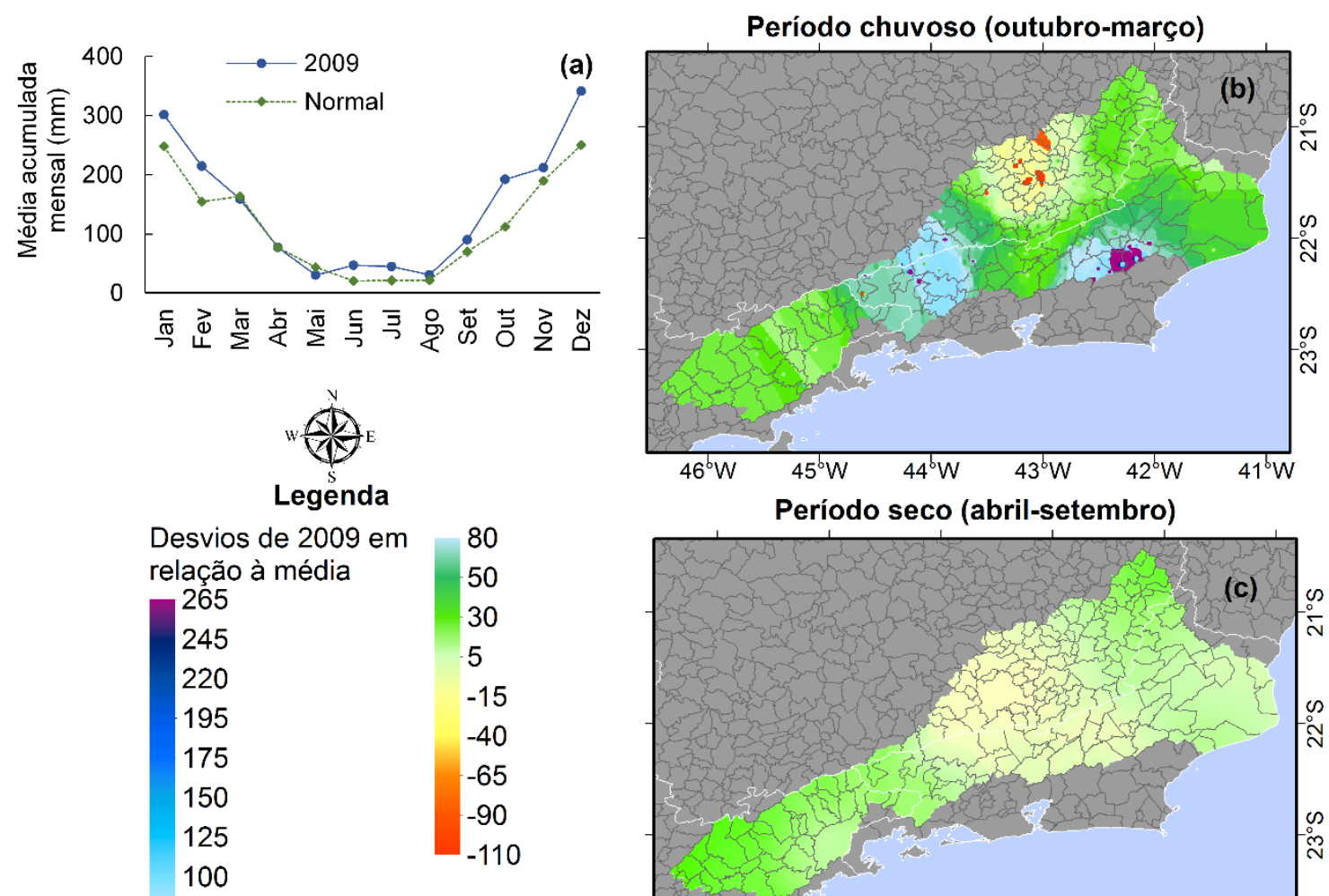

Fonte de dados: Rede Hidrometeorológica Nacional (2019); SIGA CEIVAP (2019); IBGE (2019) Datum: SIRGAS 2000

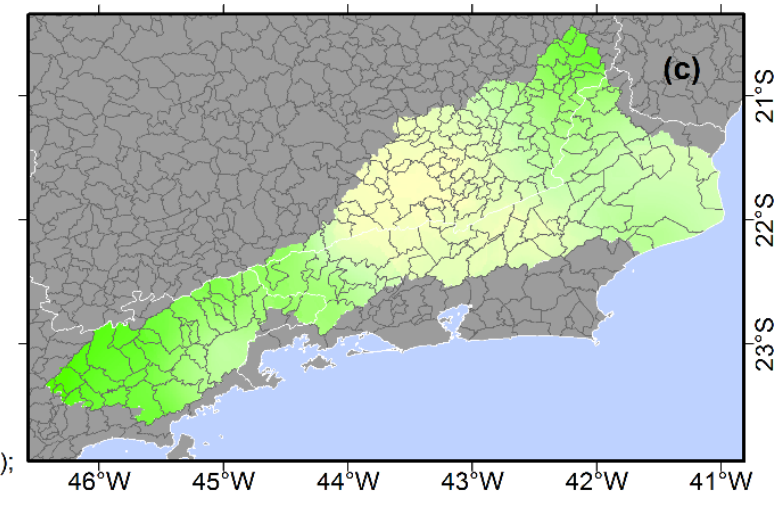

Figura 7 - a) Variação temporal da precipitação acumulada mensal de 2014 e a precipitação acumulada média (1988-2018) da bacia; b) Distribuição espacial dos desvios de precipitação em 2009 em relação à precipitação acumulada média (19882018) da bacia para o semestre chuvoso; c) Distribuição espacial dos desvios de precipitação em 2009 em relação à precipitação acumulada média (1988-2018) da bacia para o semestre seco.

Conforme apreendido na Figura 7a, os meses de janeiro, fevereiro, junho, julho e de setembro a dezembro de 2009 caracterizaram-se por pluviosidades médias consideravelmente elevadas, superiores à precipitação acumulada média para a bacia.

No semestre mais chuvoso, o desvio da precipitação em relação à média de 1988 a 2018 chegou a superar +265 mm/mês em alguns pontos, sobretudo na região serrana do Rio de Janeiro. Ainda assim, principalmente na região do CBH COMPÉ, foram observados pontos de pluviometria até $110 \mathrm{~mm}$ inferior à média de 1988-2018 (Figura 7b). No restante da bacia, os desvios do período mantiveram-se majoritariamente entre +15 e $+50 \mathrm{~mm} / \mathrm{mês}$ no semestre mais chuvoso.

No semestre mais seco, entre os meses de abril e setembro, as anomalias positivas foram mais brandas, mantendo-se inferior a $+30 \mathrm{~mm} / \mathrm{mês}$ na maior parte da bacia (Figura 7c). Anomalias negativas ocorreram majoritariamente na região central da bacia, em pontos dos CBHs Preto Paraibuna, Médio Paraíba do Sul, Rio Dois Rios e Piabanha. Os resultados corroboram com o estudo de Moraes e Nery (2014), que expôs a variabilidade 
espacial das anomalias positivas na precipitação acumulada em 2009 na região do $\mathrm{CBH}$ PS, chegando a superar em $700 \mathrm{~mm}$ a chuva acumulada anual esperada.

Acredita-se que dentre os fatores relacionados à variação interanual de chuvas na região sudeste esteja o El Niño Oscilação Sul (ENOS), fenômeno caracterizado por alterações atípicas na temperatura do Pacífico Tropical (GOIS et al., 2019; BORSATO et al., 2012; MORAES E NERY, 2014; BORSATO et al., 2012; FIGUEIRÓ E NETTO, 2011). Em anos de El Niño, nos quais se observam temperaturas oceânicas mais elevadas, espera-se um favorecimento da pluviometria na região sudeste, ao passo em que, nos eventos de La Niña, onde há um resfriamento atípico do oceano Pacífico Tropical, espera-se o inverso (MORAES E NERY, 2014; BORSATO et al., 2012; FIGUEIRÓ E NETTO, 2011). Esse aspecto pode ser observado durante os anos de 2008 e 2009 (Figura 4; Figura 5), caracterizados pela transição entre eventos de La Niña e El Niño, seguida do estabelecimento de um El Niño em 2009 (NOAA, 2020; GOIS et al., 2019).

\subsection{ANÁLISE DE TENDÊNCIAS TEMPORAIS DA PRECIPITAÇÃO}

A Figura 8 ilustra as estações cuja tendência temporal da precipitação diária máxima mensal e o número de dias de chuva se mostraram significativas a $95 \%$ de confiança.

Verifica-se, assim, que no caso da precipitação diária máxima mensal, no semestre mais chuvoso, das 86 estações selecionadas neste estudo: $81,4 \%$ não demonstraram tendências temporais significativas, a $95 \%$ de confiança; $14,0 \%$ apresentaram tendências de acréscimo; e 4,7\% apresentaram tendências significativas de decréscimo na chuva máxima mensal. Para o semestre de seca, $88,4 \%$ das estações não apresentaram evidências estatísticas de tendências, sendo que $7,0 \%$ e $4,7 \%$ demonstraram tendências de acréscimo e decréscimo, respectivamente. Portanto, como resposta à tendência de acréscimo nas precipitações máximas diárias, evidencia-se a possibilidade de aumento do risco de inundações (REGOTO et al., 2018) em diferentes pontos da bacia (Figura 8).

As tendências temporais foram mais evidentes nas distribuições de número de dias de chuva mensais em relação às precipitações diárias máximas mensais (Figura 8). No semestre mais chuvoso, $19,8 \%$ das estações apresentaram tendências de decréscimo e cerca de $20,9 \%$ tendências de acréscimo, a 95\% de confiança. Já entre abril e setembro, 22,9\% apresentaram tendências significativas de decréscimo, ao passo que 19,8\% demonstraram tendência significativa de acréscimo. Portanto, percebe-se que não há uma situação hegemônica de tendências nas séries históricas de precipitações da bacia do Rio Paraíba do Sul, apesar da manutenção do sentido da tendência (positiva ou negativa) nas estações que apresentaram resultados significativos tanto no semestre de seca quanto no semestre de chuva. 
Período chuvoso (outubro-março)

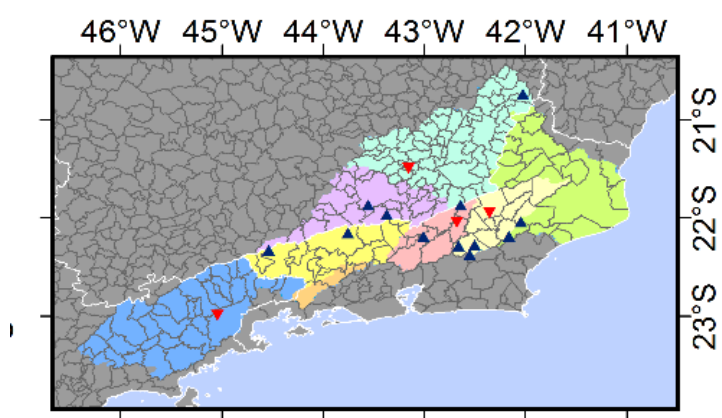

Precipitação diária máxima mensal

$46^{\circ} \mathrm{W} 45^{\circ} \mathrm{W} 44^{\circ} \mathrm{W} 43^{\circ} \mathrm{W} 42^{\circ} \mathrm{W} 41^{\circ} \mathrm{W}$

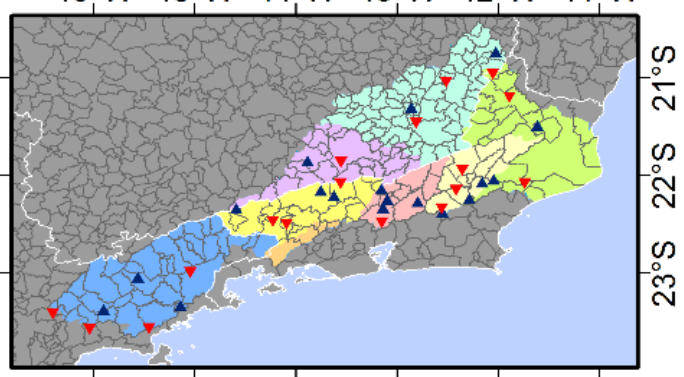

Número de dias de chuva

\section{Período seco (abril-setembro)}

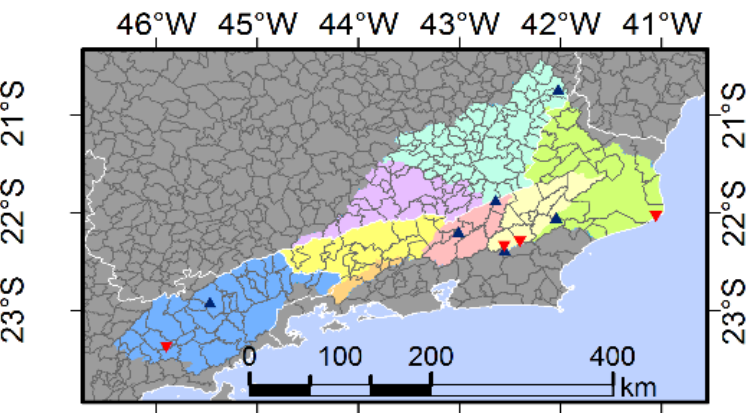

Precipitação diária máxima mensal

$46^{\circ} \mathrm{W} 45^{\circ} \mathrm{W} 44^{\circ} \mathrm{W} 43^{\circ} \mathrm{W} 42^{\circ} \mathrm{W} 41^{\circ} \mathrm{W}$

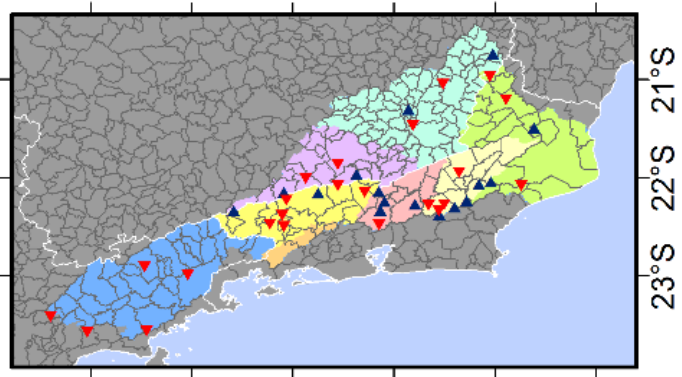

Número de dias de chuva

Legenda

- Tendência de acréscimo

v Tendência de decréscimo

$\checkmark$ Limites estaduais

$\checkmark$ PS (São Paulo)
3 Guandu

Médio Paraíba do Sul

Baixo Paraíba do Sul

Piabanha

COMPÉ

Preto Paraibuna

Rio Dois Rios
Fonte de dados:

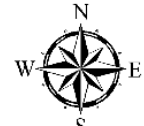

Rede Hidrometeorológica

Nacional (2019);

SIGA CEIVAP (2019);

IBGE (2019)

Datum: SIRGAS 2000

Figura 8 - Análise de tendência temporal da precipitação diária máxima mensal e do número de dias de chuva no mês nas estações pluviométricas nos semestres de chuva e seca

A Figura 9 apresenta a magnitude da tendência a partir de parâmetros Sen's slope, obtidos pela análise da precipitação diária máxima dos 186 meses pertencentes aos semestres chuvosos (de outubro a março) e dos 186 meses dos semestres secos (de abril a setembro) contidos na série temporal de estudo (1988-2018). Foram identificados acréscimos significativos de 0,0007 mm/mês a $0,0031 \mathrm{~mm} / \mathrm{mês}$ na magnitude das precipitações diárias máximas do semestre mais chuvoso (outubro a março), evidenciando, portanto, um incremento na probabilidade de ocorrência de eventos extremos diários de chuva em até $10 \%$ da área total da bacia (Figura 9). O aumento máximo $(0,0031 \mathrm{~mm} / \mathrm{mês}$ ) foi identificado na estação 2143016, localizada em Juiz de Fora - MG. Os decréscimos variaram de $-0,0016 \mathrm{~mm} / \mathrm{mês}$ a $-0,0010 \mathrm{~mm} / \mathrm{mês,} \mathrm{com} \mathrm{o} \mathrm{máximo}$ $(-0,0016 \mathrm{~mm} / \mathrm{mês})$ previsto para o município de Sumidouro - RJ (estação 2242029). 
Para o semestre de seca, foram estimadas alterações significativas de $0,001 \mathrm{~mm} / \mathrm{mês}$ a 0,0014 mm/mês, sendo o maior decréscimo identificado para a estação 2242025 e o maior acréscimo para a estação 2242024, ambas localizadas em diferentes pontos do município de Nova Friburgo - RJ, a $1.191 \mathrm{~m}$ e $1.086 \mathrm{~m}$ de altitude, respectivamente.

Conforme mencionado, parte das estações pluviométricas apresentaram tendências de diminuição do número de dias de chuva mensal dos semestres chuvoso e seco (19,8\% e $22,9 \%$, respectivamente), aspecto que pode significar a intensificação de eventos de estiagem nesses pontos. Evidenciaram-se decréscimos chegando a $-0,0014 \mathrm{dia} /$ mês entre outubro e março e $-0,0017$ $\mathrm{dia} /$ mês para os meses de abril e setembro, podendo ocorrer em até $25 \%$ da área total da bacia entre abril e setembro e em até $30 \%$ entre outubro e março. Sobretudo no semestre de baixa pluviosidade (abril e setembro), a tendência de redução do número de dias de chuva pode implicar diretamente em agravos de eventos de seca nessas áreas, podendo comprometer setores diversos, como a agricultura e o abastecimento público (CAVALCANTI e MARQUES, 2016; GALVÃO e BERMANN, 2015).

Foi também analisado se nas estações com tendência de acréscimo na precipitação diária haveria tendência de diminuição de dias chuvosos, o que indicaria uma maior vulnerabilidade a inundações. A única estação que apresentou esse comportamento foi a 2143016, localizada em Juiz de Fora MG. 
Período chuvoso (outubro-março)

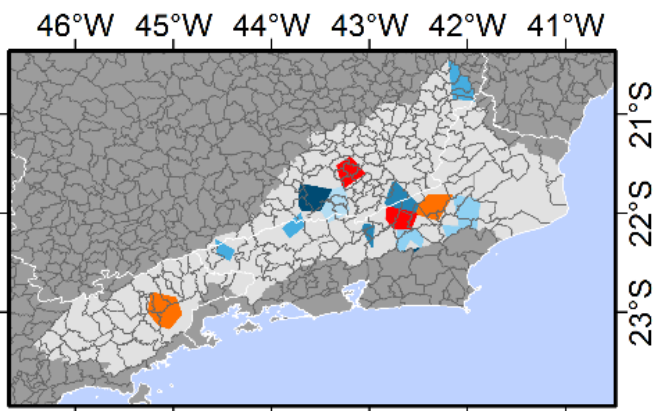

Precipitação diária máxima mensal ${ }^{*}$

$46^{\circ} \mathrm{W} 45^{\circ} \mathrm{W} 44^{\circ} \mathrm{W} 43^{\circ} \mathrm{W} 42^{\circ} \mathrm{W} 41^{\circ} \mathrm{W}$

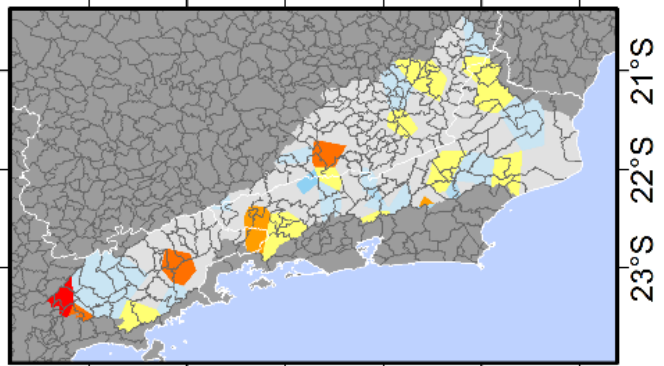

Número de dias de chuva ${ }^{* \star}$

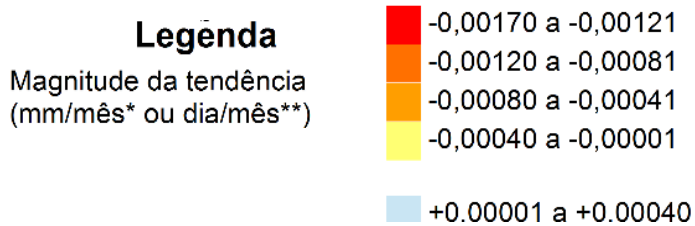

\section{Período seco (abril-setembro)}

$46^{\circ} \mathrm{W} 45^{\circ} \mathrm{W} 44^{\circ} \mathrm{W} 43^{\circ} \mathrm{W} 42^{\circ} \mathrm{W} 41^{\circ} \mathrm{W}$

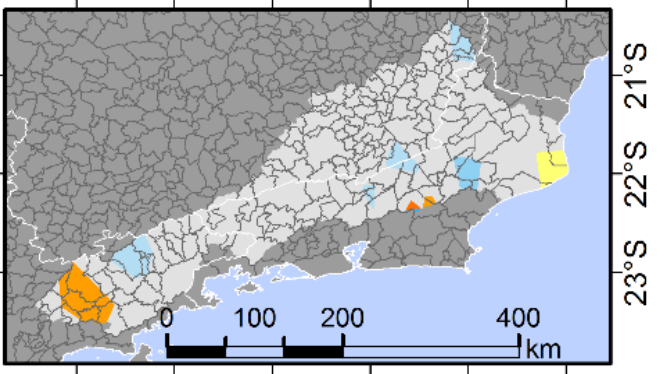

Precipitação diária máxima mensal* $46^{\circ} \mathrm{W} 45^{\circ} \mathrm{W} 44^{\circ} \mathrm{W} 43^{\circ} \mathrm{W} 42^{\circ} \mathrm{W} 41^{\circ} \mathrm{W}$

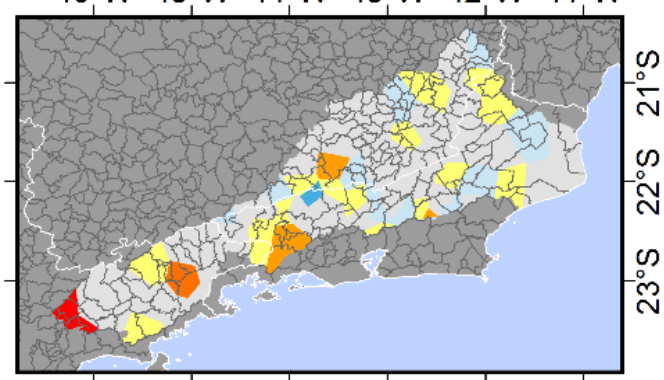

Número de dias de chuva**

$+0,00041 \mathrm{a}+0,00080$

$+0,00081 \mathrm{a}+0,00120$

$+0,00121 \mathrm{a}+0,00170$

$+0,00171 \mathrm{a}+0,00240$

$+0,00241 \mathrm{a}+0,00320$
Fonte de dados:

Rede Hidrometeorológica Nacional (2019);

SIGA CEIVAP (2019);

IBGE (2019).

Datum: SIRGAS 2000

Figura 9 - Magnitude das tendências temporais da precipitação diária máxima mensal e do número de dias de chuva no mês, obtidas pelo parâmetro Sen's slope (SEN, 1968) e espacializadas por polígonos de Thiessen (1911)

Tais resultados revelam, portanto, o indício de alterações nos padrões pluviométricos em diferentes pontos da bacia do Rio Paraíba do Sul ao longo do período avaliado. Diversos autores, bem como relatórios publicados pelo IPCC (2013), sugerem que tais alterações possam ser resultado de mudanças climáticas, principalmente no caso do favorecimento de eventos de inundações e secas (IPCC, 2013; BURN et al., 2011; SHAHID, 2011; VILLARINI et al., 2011; SANCHES et al., 2013; ZHANG e CONG, 2014; PIAZZA et al., 2016; SALVIANO et al., 2016; SILVA, 2017; REGOTO et al., 2018; ALMEIDA et al., 2019; SANTOS et al., 2020).

Estudos anteriores também expuseram alterações pluviométricas significativas distribuídas ao longo das áreas, sem um padrão específico sazonal ou espacial. Apesar de serem evidenciadas tendências significativas nas precipitações médias da bacia do Rio Paraíba do Sul a partir de dados dos anos de 1900 a 2017, conforme Andrade e Ribeiro (2018), não há um padrão definido de decréscimo ou acréscimo local das chuvas médias, muito embora tenham 
sido expostos pontos de maior vulnerabilidade na parte da bacia pertencente ao estado de São Paulo.

Salviano et al. (2016) também expuseram esse fator. No referido trabalho, é possível verificar pontos pertencentes à bacia do Rio Paraíba do Sul com tendências positivas significativas para as precipitações médias mensais dos meses de março, abril, novembro e dezembro, a partir da avaliação de tendências pluviométricas do Brasil por meio de dados de 1961 a 2011. Nesse sentido, explicitam-se incertezas acerca do comportamento pluviométrico médio da bacia ao longo dos próximos anos.

O comportamento de não uniformidade das tendências pluviométricas também foi destacado em abundância na literatura (SANTOS et al., 2020; PIAZZA et al., 2016; SANCHES et al., 2013; VILLARINI et al., 2011), assim como tendências de acréscimo em eventos extremos de chuva, Além dos indícios de intensificação de eventos de secas (REGOTO et al., 2018; SILVA et al., 2017; ZHANG e CONG, 2014; BURN et al., 2011; SHAHID, 2011).

Nesse sentido, evidencia-se a aplicabilidade dessas análises na identificação de pontos de maior vulnerabilidade hídrica, não só de escassez, mas ainda de maior suscetibilidade de aumento de chuvas extremas, podendo levar a alagamentos, comprometimentos na drenagem urbana, agravos nos processos erosivos e aumento do risco de exposição da população à vetores e doenças (SILVA et al., 2017; ARAÚJO et al., 2008).

\section{CONCLUSÕES E RECOMENDAÇÕES}

Observou-se com esse estudo que a bacia apresenta uma grande variação pluviométrica intra-anual, conforme esperado visto que a região é influenciada pela dinâmica de sistemas meteorológicos distintos, tais como o Anticiclone Subtropical do Atlântico Sul (ASAS), o Jato de Baixos Níveis (JBN) e a Zona de Convergência do Atlântico Sul (ZCAS). Também há grande variação espacial da pluviometria, evidenciada por fatores como a altitude, maritimidade e continentalidade.

Foram verificados períodos de pluviometria atipicamente elevada nos anos de 1996, 2008 e 2009, com desvios em relação à média chegando a superar $+265 \mathrm{~mm} / \mathrm{mês}$ em alguns pontos no ano de 2009. Já o ano de 2014 apresentou tanto um menor número médio de dias de chuva quanto menores volumes acumulados nos dias chuvosos, com desvios médios mensais superiores a $-200 \mathrm{~mm} / \mathrm{mês}$. Em comparação com a precipitação acumulada média para a bacia, observou-se que a pluviometria de 2014 foi cerca de $155 \%$ inferior à precipitação acumulada média de 1988 a 2018.

Em 20,9\% das estações pluviométricas foram observadas tendências de acréscimo nas precipitações do semestre chuvoso, a 95\% de confiança, e em $22,9 \%$ tendências significativas de decréscimo no número de dias de chuva do semestre de seca. As análises sugeriram ainda incrementos na probabilidade de ocorrência de eventos extremos diários de chuva em até $10 \%$ da área total da bacia. Tais resultados revelam, portanto, o indício de alterações nos padrões pluviométricos em diferentes pontos da bacia do Rio Paraíba do Sul ao longo do período avaliado. Para atestar reais mudanças deve-se, porém, permanecer com estudos de avaliação de séries históricas para toda a bacia, e ampliar as séries 
em estudo para mais anos de dados. Destaca-se ainda a relevância de tais estudos na elaboração de prognósticos, contribuindo com a tomada de decisão na gestão de recursos hídricos.

\section{REFERÊNCIAS BIBLIOGRÁFICAS}

AGEVAP. Associação Pró-gestão das Águas da Bacia Hidrográfica do Rio Paraíba do Sul. Plano de Recursos Hídricos da Bacia do Rio Paraíba do Sul - Resumo. Rio de Janeiro: AGEVAP. 2006.

AGEVAP. Associação Pró-gestão das Águas da Bacia Hidrográfica do Rio Paraíba do Sul. Plano integrado de recursos hídricos da bacia hidrográfica do Rio Paraíba do Sul e planos de ação de recursos hídricos das bacias afluentes. Rio de Janeiro: AGEVAP. 2014.

AGEVAP. Associação Pró-gestão das Águas da Bacia Hidrográfica do Rio Paraíba do Sul. Relatório técnico da bacia do Rio Paraíba do Sul: subsídios às ações de melhoria da gestão. Rio de Janeiro: AGEVAP. 2011.

ALMEIDA, G. G. L.; PAIVA, A. L. R.; OLIVEIRA, L. M. M.; LEONARDO, H. R. A. L. Análise de índices climáticos para avaliação do efeito de mudanças climáticas. Revista Brasileira de Geografia Física, v. 13, n. 01, p. 01-17, 2020.

ANDRADE, M. P.; RIBEIRO C. B. M. Análise de tendências no comportamento da chuva na bacia do rio Paraíba do Sul. In: III Simpósio de Recursos Hídricos da Bacia do Rio Paraíba do Sul. Anais... Juiz de Fora: UFJF. n.p. 2008.

ARAÚJO, L. E.; MORAES NETO, J. M.; SOUSA, F. A. S. Classificação da precipitação e da quadra chuvosa da Bacia do Rio Paraíba utilizando índice de anomalia de chuva (IAC). Ambiente \& Água, v. 4, n. 3, p. 93-110, 2009.

ARAÚJO, L. E.; SOUSA, F. A. S.; RIBEIRO, M. A. F. M.; SANTOS, A. S.; MEDEIROS, P. C. Análise estatística de chuvas intensas na bacia hidrográfica do Rio Paraíba. Revista Brasileira de Meteorologia, v. 23, n. 2, p. 162-169, 2008.

BRASIL. Lei n॰9433/1997, de 8 de janeiro de 1997. Diário Oficial [da] República Federativa do Brasil, Poder Executivo, Brasília, DF. 08 jan.1997. Seção III. 1997.

BURN, D. H.; RAMI, M.; ZHANG, K.; WHITFIELD, P. H. Trends and Variability in Extreme Rainfall Events in British Columbia. Canadian Water Resources Journal, v. 36, n. 1, p. 67-82, 2011.

CARVALHO, S. M. I.; SHOEGIMA, T. F.; NERY, J. T. Análise quantitativa e espacial de distribuição dos períodos de chuva intensa e seca na Bacia Hidrográfica do Rio Paraíba do Sul. In: XVII Simpósio Brasileiro de Geografia Física Aplicada/I Congresso nacional de Geografia Física - Instituto de Geociências (UNICAMP). Anais..., p. 1634-1646, 2017.

CAVALCANTI, B.S.; MARQUES, G. R. G. Recursos hídricos e gestão de conflitos: A bacia hidrográfica do Rio Paraíba do Sul a partir da crise hídrica de 20142015. Revista de Gestão dos Países de Língua Portuguesa, v. 5, n. 1, p. 04-16, 2016.

CEIVAP. Comitê de Integração da Bacia Hidrográfica do Rio Paraíba do Sul. Planos de Bacia. Resende: CEIVAP. 2020a. 
CEIVAP. Comitê de Integração da Bacia Hidrográfica do Rio Paraíba do Sul. Dados Gerais. Resende: CEIVAP. 2020b.

CONFALONIERI, U.; LIMA, A.; BRITO, I.; QUINTÃO, A. Social, environmental and health vulnerability to climate change in the Brazilian Northeastern Region. Climatic Change, v. 127, n. 1, p. 123-137, 2014.

CRESSIE, N. The origins of kriging. Mathematical Geology, v. 22, p. 239-252, 1990.

DEMANBORO, A. C. Gestão ambiental e sustentabilidade na macrometrópole paulista - Bacia do Rio Paraíba do Sul. Sociedade \& Natureza, v. 27, n. 3, p. 515-530, 2015.

DINIZ, J. M. T., 2013. Variabilidade da precipitação e do número de dias com chuvas de duas cidades distintas da Paraíba. Holos 29(3), 171-180.

FIGUEIRÓ, A. S.; NETTO, A. L. C. 2011. Climatic variability and pluviometric trends in a humid tropical environment at Resende municipality-middle Paraíba do Sul river valley (Rio de Janeiro-Brazil). Brazilian Geographical Journal: Geosciences and Humanities research medium, v. 2, n. 2, p. 256-273, 2011.

FISCH, G.; SANTOS, T. A.; SILVA, R. C. Water security in the Vale do Paraiba's basin: future scenarios. Ambiente \& Água, v. 12, n. 6, p. 881-887, 2017.

FREITAS, M. A. S. Um sistema de suporte à decisão para o monitoramento de secas meteorológicas em regiões semiáridas. Revista Tecnologia, p. 84-95, 2005.

FREITAS, M. J. C. C.; KAETSU, P. T. 2015. A gestão dos recursos hídricos e da estiagem no Oeste Catarinense: contribuição para uma análise sistêmica complexa. Labor \& Engenho, v. 9, n. 4, p. 34-50, 2015.

GALVÃO, J.; BERMANN, C. Crise hídrica e energia: conflitos no uso múltiplo das águas. Estudos avançados, v. 29, n. 84, p. 43-68, 2015.

HIDROWEB. Estações. Disponível em: <http://www.snirh.gov.br/hidroweb/publico/mapa_hidroweb.jsf>. Acesso em: 13 jan. 2020.

HIRSCH, R. M.; ALEXANDER, R. B.; SMITH, R. A. Selection of methods for the detection and estimation of trends in water quality. Water Resources Research, v. 27, p. 803-813, 1991.

HURD, B.; ROUHI-RAD, M. Estimating economic effects of changes in climate and water availability. Climatic Change, v. 117, n. 3, p. 575-584, 2013.

IBGE. Instituto Brasileiro de Geografia e Estatística. Bases cartográficas. Disponível: https://mapas.ibge.gov.br/bases-e-referenciais/basescartograficas.html. Acesso: 18 set. 2019.

IGAM. Instituto Mineiro de Gestão das Águas. Gestão de Recursos Hídricos. Disponível: http://www.igam.mg.gov.br/banco-de-noticias/1-ultimasnoticias/588-minas-rio-e-sao-paulo-discutem-gestao-de-recursos-hidricos. Acesso: 13 jan. 2020.

JARDIM, C. H.; MOURA, F. P. Variações dos totais de chuvas e temperatura do ar na bacia do rio pandeiros, norte do estado de minas gerais-brasil: articulação com fatores de diferentes níveis escalares em área de transição climática de 
cerrado para semiárido. Revista Brasileira de Climatologia, Edição Especial Dossiê Climatologia de Minas Gerais, 172-189.

KENDALL, M. A., STUART, A, 1967. The advanced theory of statistics. 2. ed. Londres: Charles Griffin.

KÖPPEN, W. Das geographische System der Klimate. In: KÖPPEN, W.; GEIGER, R. (Eds.) Handbuch der Klimatologie. Berlin: Gebruder Borntraeger, v. 1, p. 144, part C, 1936.

KRUSKAL, W. H.; WALLIS, W. A. Use of ranks in one-criterion variance analysis. Journal of the American Statistical Association, v. 47, p. 583-621, errata v. 48, p. 907-911, 1952.

LUQUE, G. M.; HOCHBERG, M. E.; HOLYOAK, M.; HOSSAERT, M.; GAILL, F.; COURCHAMP, F., 2013. Ecological effects of environmental change. Ecology Letters, v. 16, n. s1, p. 1-3, 2013.

MANIÇOBA, R.M.; SOBRINHO, J.E.; GUIMARÃES, I.T.; CAVALCANTE JUNIOR, E.G.; SILVA, T.T.F.; ZONT, J.H. Índice de anomalias de chuva para diferentes mesorregiões do Estado do Rio Grande do Norte. Revista Brasileira de Geografia Física, v. 10, n. 4, p. 1110-1119, 2017.

MANN, H. B. Non-parametric tests against trend. Econometrica, v. 13, p. 245259, 1945.

MARENGO, J. A.; ALVES, L. M. Tendências Hidrológicas da Bacia do Rio Paraíba do Sul. Revista Brasileira de Meteorologia, v. 20, p. 215-226, 2005.

MARENGO, J. A.; ALVES, L. M. Crise hídrica em São Paulo em 2014: seca e desmatamento. Geousp - Espaço e Tempo (Online), v. 19, n. 3, p. 485-494, 2015.

MARENGO, J. A.; VALVERDE, M. C. Caracterização do clima no Século XX e Cenários de Mudanças de clima para o Brasil no Século XXI usando os modelos do IPCC-AR4. Revista Multiciência, v. 8, p. 5-28, 2007.

MATSUSHITA, T. L.; GRANADO, D. W. A crise hídrica no Brasil e seus impactos no desenvolvimento econômico e ambiental. Revista Thesis Juris, v. 6, n. 1, p. 167-185, 2017.

MCLEOD, A. I. Package 'Kendall'. 2015. Disponível em: <https://cran.rproject.org/web/packages/Kendall/Kendall.pdf>. Acesso em: 30 jan. 2020.

MORAES, M. P. C.; NERY, J. T. Análise da variabilidade pluvial na unidade de gerenciamento de recursos hídricos do Paraíba do Sul (UGHRI-2). Revista Brasileira de Climatologia, v. 14, p. 264-274, 2014.

NIMER, E. Climatologia da região sudeste do Brasil: Introdução à climatologia dinâmica - Subsídios à geografia regional do Brasil. Revista Brasileira de Geografia, v. 34, n. 1, p. 3-48, 1972.

NOAA. National Oceanic and Atmospheric Administration. Cold \& Warm Episodes by Season. 2020.2 Disponível em: <http://www.cpc.ncep.noaa.gov/products/analysis_monitoring/ensostuff/ensoye ars.shtml>. Acesso em: 23 abr. 2020.

NOBRE, C. A.; MARENGo, J. A.; SELUCHI, M. E.; CUARTAS, L. A.; ALVES, L. M. Some characteristics and impacts of the drought and water crisis in 
southeastern Brazil during 2014 and 2015. Journal of Water Resource and Protection, v. 8, p. 252-262, 2016.

NUNES, F. T.; VASCONCELOS JÚNIOR, F.C.; SILVEIRA, C.S. Avaliação Interanual das Anomalias de Chuvas da Bacia Hidrográfica do Rio Mundaú Ceará. Revista Brasileira de Geografia Física, v. 12, n. 1, p. 022-038, 2019.

PEARSON, $K$. On the criterion, that a given system of deviations from the probable in the case of a correlated system of variables is such that it can be reasonably supposed to have arisen from random sampling. Philosophical Magazine Series 5, v. 50, p. 157-175, 1900.

PIAZZA, G. A., TORRES, E., MOSER, P., GOTARDO, R., KAUFMANN, V., PINHEIRO, A. Análise espacial e temporal dos dados de precipitação das estações de entorno da bacia do Ribeirão Concórdia, Lontras (SC) visando sua inserção no contexto de mudanças climáticas. Revista Brasileira de Meteorologia, v. 31, n. 4, p. 580-592, 2016.

REDE HIDROMETEOROLÓGICA NACIONAL. Mapas e publicações. Disponível: http://www.cprm.gov.br/publique/Hidrologia/Mapas-e-Publicacoes-173. Acesso: 18 set 2019.

REGOTO, P.; DERECZYNSKI, C.; SILVA, W. L.; SANTOS, R.; CONFALONIERI, U. Tendências de Extremos de Precipitação para o Estado do Espírito Santo. Anuário do Instituto de Geociências, v. 41, n. 1, p. 365-381, 2018.

SALVIANO, M. F.; GROPPO, J. D.; PELLEGRINO, G. Q. Análise de tendências em dados de precipitação e temperatura no Brasil. Revista Brasileira de Meteorologia, v. 31, p. 64-73, 2016.

SANCHES, F. O., VERDUM, R., FISCH, G., 2013. Estudo de tendência de chuvas de longo prazo. Ambiente \& Água 8(3), 214-228.

SANT'ANNA NETO, J. L. Decálogo da climatologia do sudeste brasileiro. Revista Brasileira de Climatologia, v. 1, n. 1, 2005.

SANTOS, J. R. N.; ARAÚJO, M. L. S.; SILVA JÚNIOR, C. H. L.; SANTO, J. S.; ALMEIDA, J. L.; LIMA, T. V.; SOUSA, L. V. P.; AGUIAR, P. H. M.; SILVA, F. B. Tendências de extremos climáticos na região de transição amazônia-cerrado no estado do maranhão. Revista Brasileira de Climatologia, v. 26, p. 130-154, 2020.

SEN, P. K., 1968. Estimates of the regression coefficient based on Kendall“s tau. Journal of the American Statistical Association 63, 1379-1389.

SHAHID, S. Trends in extreme rainfall events of Bangladesh. Theoretical \& Applied Climatology, v. 104, n. 3-4, p. 489-499, 2011.

SIGA CEIVAP. Sistema de Informações Geográficas e Geoambientais da Bacia Hidrográfica do Rio Paraíba do Sul. Disponível: http://sigaceivap.org.br/map\#. Acesso: 18 set. 2019.

SILVA, J. P. R.; REBOITA, M. S.; ESCOBAR, G. C. J. Caracterização da Zona de Convergência do Atlântico Sul em campos atmosféricos recentes. Revista Brasileira de Climatologia, v. 25, p. 355-377, 2019.

SILVA, R. O. B.; MONTENEGRO, S. M. G. L.; SOUZA, W. M. Tendências de mudanças climáticas na precipitação pluviométrica nas bacias hidrográficas do 
estado de Pernambuco. Engenharia Sanitária e Ambiental, v. 22, n. 3, p. 579589, 2017.

SOBRAL, B. S.; OLIVEIRA-JÚNIOR, J. F.; GOIS, G. TERASSI, P. M. B.; MUNIZJÚNIOR, J. G. R. Variabilidade espaço-temporal e interanual da chuva no estado do Rio de Janeiro. Revista Brasileira de Climatologia, v. 22, p. 281-308, 2018.

SOUZA, J. O. P.; ALMEIDA, J. D. M.; CORREA, A. C. B. Caracterização e espacialização da precipitação em bacia hidrográfica com relevo complexo: sertão central pernambucano - bacia do Riacho do Saco. Revista de geografia (UFPE), v. 32, n. 2, p. 106-126, 2015.

THIESSEN, A. H. Precipitation for large areas. Monthly Weather Review, v. 39, p. 1082-1084, 1911.

TUCCI, C. E. M. Hidrologia: ciência e aplicação. 2. ed. Porto Alegre: Editora da Universidade. 1997.

USGS. U.S. Geological Survey. Reprocessing by the GLCF. 2004. (1, 3, 30) ArC Second SRTM Elevation, Reprocessed to GeoTIFF. College Park, Maryland: The Global Land Cover Facility. Version 1.0.

VILLARINI, G.; SMITH, J. A.; NTELEKOS, A. A.; SCHWARZ, U. Annual maximum and peaks-over-threshold analyses of daily rainfall accumulations for Austria. Journal of Geophysical Research: atmospheres (online), v. 116, n. D5, 2011. Disponível em: <https://www.doi.org/10.1029/2010JD015038>. Acesso em: 20 mar. 2020.

ZEILHOFER, P.; LIMA, E. B. R.; SANTOS, F. M.; RIGO JÚNIOR, L. O. Um ambiente SIG para modelagem integrada da qualidade da água utilizando Qual2e. Caminhos de Geografia, v. 8, p. 107-125, 2003.

ZHANG, X.; CONG, Z. Trends of precipitation intensity and frequency in hydrological regions of China from 1956 to 2005. Global and Planetary Change, v. 117, p. $40-51,2014$. 